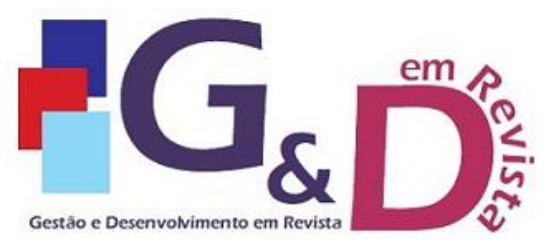

\title{
VOLATILIDADE DOS PREÇOS DE EXPORTAÇÃO DA SOJA E DO MILHO NO ESTADO DO PARANÁ E A PANDEMIA DA COVID-19: UM ESTUDO TEMPORAL
}

\author{
Edson Santos Melo \\ Doutorando no Programa de Pós-Graduação em Desenvolvimento Regional da UTFPR Campus Pato \\ Branco-PR. Atualmente é professor assistente da Universidade Estadual do Oeste do Paraná - \\ UNIOESTE campus de Francisco Beltrão. \\ E-mail: edson.melo@unioeste.br
}

\section{Douglas Marcos Ferreira}

Doutor em Economia Aplicada pela Universidade Federal de Viçosa - UFV. Professor Adjunto da Universidade Federal de São João del-Rei e do Programa de Pós-Graduação em Desenvolvimento, Planejamento e Território (PGDPLAT/UFSJ).

E-mail: douglasferreira@ufsj.edu.br

\section{Salatiel Turra}

Doutor em Ciências Econômicas pela Universidade do Estado do Rio de Janeiro (UERJ). Atualmente é Chefe do Departamento de Economia Rural da Secretaria de Estado da Agricultura e do Abastecimento do Paraná.

E-mail: salatielturra@gmail.com

\section{Resumo}

No Brasil, o estado do Paraná possui significativa relevância na produção e exportação de diversos produtos agrícolas. Desde o início da pandemia da Covid-19 verificou-se a oscilação nos preços de diversas commodities, destacando-se os aumentos acentuados nos preços da soja e do milho. Nesse sentido, o presente trabalho utilizou modelos de volatilidade condicional para estudar os comportamentos das volatilidades dos preços de exportação da soja e do milho, no estado do Paraná, no período entre janeiro de 2019 e março de 2021. Os resultados indicaram que o processo de alta nos preços de exportação das duas commodities, após o início da pandemia, foi acompanhado pelo aumento da volatilidade dos preços. Ressalta-se ainda que foi identificada alta persistência de choques nos preços da soja e do milho no período analisado.

Palavras-chave: Preços de exportação; Produtos agrícolas; Covid-19; Modelos de heterocedasticidade condicional.

\begin{abstract}
In Brazil, the state of Paraná has significant relevance in the production and export of various agricultural products. Since the beginning of the Covid-19 pandemic, there has been a fluctuation in the prices of several commodities, highlighting the increases in soybeans and corn prices. In this sense, the present work used conditional heteroscedastic models to study the behavior of the volatility of soybean and corn export prices, in the state of Paraná, in the period between January 2019 and March 2021. The results indicated that the process of the rise in export prices for the two commodities, after the onset of the pandemic, was accompanied by increased price volatility. It is also noteworthy that a high persistence of shocks in soybean and corn prices was identified in the period analyzed.
\end{abstract}

Keywords: Export prices; Agricultural products; Covid-19; Conditional heteroscedastic models. 


\section{Introdução}

Por definição, commodity é o termo designado para se referir a uma mercadoria em estado bruto, podendo ser in natura, cultivado ou de extração mineral. Ademais, são produtos que podem conter um pequeno grau de industrialização, porém, sem deixar de apresentar as características de possuírem qualidade homogênea, serem produzidos em grande quantidade e por um número considerável de produtores. Destaca-se, ainda, que grande parte de sua negociação ocorre prioritariamente nas bolsas de valores.

Em períodos recentes, têm-se notado uma intensificação na reprimarização dos produtos exportados pelo Brasil, com acentuada magnitude no valor total das exportações relativas às commodities, muito disso impulsionado pela demanda chinesa. Dentre as commodities, compete destacar os produtos agrícolas, entre eles: soja, açúcar, carne bovina, milho e o café (BRASIL, 2021).

Em que pese tal fato, conforme o Instituto Brasileiro de Geografia e Estatística IBGE (2019), o Paraná se destaca entre as unidades da federação como um dos principais produtores de grãos do país, ficando atrás somente do estado de Mato Grosso. Uma análise mais detalhada de alguns números estaduais reforça tal ponto. Por exemplo, somente o complexo soja respondeu por $36,8 \%$ do total das exportações do estado no ano de 2020 (BRASIL, 2021). Outro aspecto a ser destacado é que, segundo o Instituto Paranaense de Desenvolvimento Econômico e Social - IPARDES (2021), no ano de 2020, apenas a agropecuária apresentou variação real positiva no PIB estadual em todos os trimestres, ao contrário da indústria e serviços, isso comparado ao mesmo trimestre do ano anterior. A Tabela 1 apresenta mais detalhes dessa variação, considerando o período do $1^{\circ}$ trimestre de 2018 ao $1^{\circ}$ trimestre de 2021. 


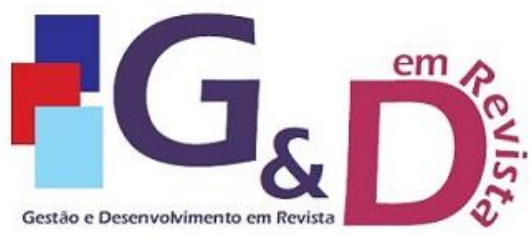

Gestão e Desenvolvimento em Revista

V. 8, N. 2, jul-dez/2021, p. 133-152.

ISSN online: $2446-8738$

Artigo recebido em: 02/08/2021

Artigo aprovado em: 27/10/2021

Tabela 1 - Variação do PIB trimestral setorial e total do Paraná (em \%), com relação ao mesmo trimestre do ano anterior - 2018 a 2021.

\begin{tabular}{c|c|c|c|c}
\hline Período & Agropecuária & Indústria & Serviços & PIB \\
\hline $2018 . I$ & $-1,99$ & $-3,55$ & 3,73 & 1,11 \\
\hline $2018 . I I$ & $-6,96$ & $-0,73$ & 2,84 & 1,36 \\
\hline 2018. III & $-16,36$ & 0,47 & 2,44 & 0,42 \\
\hline $2018 . I V$ & 9,98 & $-1,83$ & 3,14 & 2,08 \\
\hline $2019 . I$ & $-4,57$ & 2,11 & $-0,20$ & 0,20 \\
\hline $2019 . I I$ & $-7,43$ & 4,28 & $-0,06$ & 0,88 \\
\hline $2019 . I I I$ & $-1,72$ & 2,08 & $-0,04$ & 1,34 \\
\hline $2019 . I V$ & $-15,01$ & $-1,61$ & $-0,04$ & $-0,38$ \\
\hline $2020 . I$ & 19,87 & $-0,43$ & 0,28 & 3,60 \\
\hline $2020 . I I$ & 14,53 & $-15,27$ & $-7,38$ & $-7,21$ \\
\hline $2020 . I I I$ & 5,85 & $-2,09$ & $-3,78$ & $-2,82$ \\
\hline $2020 . I V$ & 12,31 & 5,65 & $-2,97$ & $-0,50$ \\
\hline $2021 . I$ & $-4,23$ & 6,59 & $-1,63$ & 0,14 \\
\hline
\end{tabular}

Fonte: Elaborado com dados do IPARDES (2021).

Contudo, nota-se que a participação da agropecuária no PIB estadual nem sempre foi positiva, pois, do terceiro trimestre de 2018 ao quarto trimestre de 2019 verificou-se variações negativas, em parte explicadas pelas adversidades climáticas, como períodos de estiagens prolongadas. Com efeito, Manfio (2020a; 2020b) destaca que o estado do Paraná enfrentou uma das principais crises hídricas da história. Entretanto, segundo Moreira (2020), apesar destas adversidades o estado produziu o maior volume de soja da sua história na safra 2019/20, ou seja, atingiu a marca de 20,8 milhões de toneladas. Contudo, nota-se que no primeiro trimestre de 2021 a agropecuária apresentou variação negativa, o que em parte se justifica pela redução no volume produzido de soja.

Para a cultura de milho, observou-se uma evolução do potencial produtivo em ambas as safras. A produtividade média da primeira safra 2019/20 evoluiu 32\% comparativamente à safra 2010. Além disso, a área cultivada do produto na primeira safra tem apresentado uma tendência de decréscimo, ao passo que ocorre uma expansão de área plantada na segunda safra (GERVÁSIO, 2020).

A soja, por sua vez, é a principal cultura que compete área de plantio na primeira safra com o milho. Assim, entre outros, são apontados como fatores dessa mudança as poucas 
opções de cultivo de inverno, a possibilidade de oferta de milho na entressafra e a opção pelo plantio da soja na safra de verão (primeira safra). Desse modo, há um deslocamento da produção de milho da primeira safra para o cultivo da soja, ocasionando a migração da maior área cultivada do milho de primeira safra para a de segunda.

Além disso, ressalta-se que um dos principais fatores que influenciam e orientam a tomada de decisão do produtor rural é o comportamento dos preços dos produtos. Nesse sentido, destaca-se que, em 2020, os produtores obtiveram acréscimo de 39\%, aproximadamente, no valor recebido pela saca da soja de $60 \mathrm{~kg}$ (MOREIRA, 2020). No caso da cultura do milho, de janeiro a novembro de 2020, o preço médio recebido pelo produtor pela saca de $60 \mathrm{~kg}$ teve um aumento de $102 \%$ em relação ao valor recebido em novembro de 2019 (GERVÁSIO, 2020).

Sendo assim, na busca de maior eficiência na alocação de seus recursos e melhores resultados econômicos, o produtor tende a se guiar pelo comportamento dos preços. Soma-se a esse fato a especificidade das commodities serem produtos precificados pelo mercado, especialmente no mercado externo. Com isso, um fator que pode impactar diretamente tanto a produção quanto a renda do produtor é a taxa de câmbio. Assim, uma depreciação cambial pode ser vantajosa para o produtor de alguma commodity na hora da comercialização do produto, uma vez que, relativamente, ele auferirá um lucro maior ao receber pela venda. Todavia, essa mesma depreciação cambial poderá prejudicar o produtor na hora do plantio, pois os custos de alguns insumos poderão tornar-se mais caros. Em que pese tal fato, segundo Nonnenberg (2021), entre janeiro de 2020 e janeiro de 2021, a taxa de câmbio real/dólar já havia se desvalorizado 29,1\%. Com isso, desde o início da pandemia, o Real foi uma das moedas que mais se desvalorizaram, principalmente entre os países emergentes. Contudo, se ampliado o período, vê-se que a desvalorização foi bem maior. Com os dados da taxa de câmbio média mensal, observa-se que a desvalorização entre janeiro de 2018 e março de 2021 já chega a 75,86\% (BANCO CENTRAL DO BRASIL, 2021).

Neste contexto, Stiglitz et al. (2006) já argumentavam que a volatilidade cambial nas economias emergentes, devido aos fluxos de capitais internacionais, tende a ser superior à dos mercados desenvolvidos. Assim, a volatilidade cambial tende a ser repassada também para os preços de exportação das commodities.

Alguns estudos já avaliaram a volatilidade nos preços da soja e do milho, porém para períodos diferentes. Por exemplo, Silva, Sáfadi e Castro Junior (2005) verificaram forte assimetria na volatilidade do retorno da soja e que os choques podem repercutir por períodos 
bem longos. Por sua vez, Campos (2007), ao analisar a volatilidade para vários produtos agropecuários nacionais, observou valores do somatório do coeficiente de reação e de persistência inferiores a 1, mas próximos à unidade. Com isso, concluiu que choques podem provocar efeitos mais rápidos sobre a volatilidade do milho no curto prazo, enquanto na série da soja tal choque demoraria mais tempo para se dissipar. Já Conte, Coronel e Amorim (2016) estudaram a volatilidade do complexo brasileiro de soja e também identificaram uma persistência na volatilidade e um período longo para sua dissipação. Além disso, os últimos autores referenciados indicaram alguns aspectos que contribuíram para a volatilidade do mercado brasileiro de soja, sendo o aumento na demanda por parte da economia chinesa como um dos fatores preponderantes.

À luz do exposto, coloca-se a seguinte questão: como se comportou a volatilidade dos preços de exportação recebidos pelos produtores paranaenses de soja e milho ao longo da pandemia da Covid-19? Portanto, diante da atual desvalorização da moeda brasileira, o presente trabalho tem como objetivo avaliar o comportamento da volatilidade dos preços de exportação recebidos pelos produtores de soja e milho no estado do Paraná, no período de janeiro de 2019 a março de 2021. Especificamente, pretende-se: i) caracterizar os clusters de alta volatilidade nas séries estudadas; ii) verificar a ocorrência de intensificação da volatilidade após o início da pandemia; e, iii) identificar qual grupo de produtores foi mais exposto à volatilidade de preços.

O presente trabalho está dividido em mais três seções, além desta introdução. A segunda expõe a metodologia e os dados utilizados; a terceira seção apresenta os resultados empíricos e as respectivas discussões; na quarta seção, segue-se as considerações finais.

\section{Metodologia}

O estudo da volatilidade dos ativos tem recebido grande importância no campo da econometria financeira. Desde o trabalho original de Engle (1982), que buscou analisar o comportamento da variância através de modelos autorregressivos condicionais (ARCH), foram desenvolvidos diversos modelos com o objetivo de modelar o processo de volatilidade condicional variante no tempo.

A análise empírica proposta neste trabalho está baseada nos modelos de volatilidade condicional, que serão estimados a fim de estudar o comportamento da volatilidade dos preços de exportação da Soja e do Milho, no estado do Paraná, no período entre janeiro de 2019 e março de 2021. Outras características que podem estar presentes na volatilidade das 
séries de preços, como assimetria e alavancagem ${ }^{1}$, também serão analisados com base nos modelos estimados.

\subsection{Retornos financeiros e suas características}

As séries financeiras utilizadas nas estimações dos modelos em geral tendem a não apresentar um processo estacionário. Assim, segundo Lütkepohl e Krätzig (2004), dada a nãoestacionariedade das séries, a análise se concentra em seus retornos. O retorno pode ser simples ou composto contínuo.

Considerando $P_{t}$ o preço de um ativo ou índice no $t$-ésimo instante de tempo, o retorno líquido simples $\left(R_{t}\right)$ pode ser obtido por:

$$
R_{t}=\frac{P_{t}-P_{t-1}}{P_{t-1}}=\frac{\Delta P_{t}}{P_{t-1}}
$$

Para o cálculo do retorno composto contínuo $\left(r_{t}\right)$, deve-se primeiro denotar $p_{t}=\ln P_{t}$, assim:

$$
r_{t}=\ln \frac{P_{t}}{P_{t-1}}=\ln \left(1+R_{t}\right)=p_{t}-p_{t-1}
$$

Logo, para pequenos valores de $R_{t}$, os valores de ambos os retornos serão próximos, como pode ser visto pela expressão $\ln \left(1+R_{t}\right) \approx R_{t}$.

Em geral, como demonstrado por Lütkepohl e Krätzig (2004) e Morettin e Toloi (2004), os retornos financeiros apresentam algumas características, as quais podem ser sumarizadas nos pontos a seguir:

i) os retornos tipicamente não são, ou pelo menos fracamente, autocorrelacionados;

ii) os quadrados dos retornos apresentam autocorrelação;

iii) a volatilidade aparece agrupada em clusters cuja variabilidade (maior ou menor) se modifica ao longo do tempo; e

iv) em consequência da característica anterior, a distribuição incondicional dos retornos rejeita a hipótese nula de normalidade. Assim, a distribuição tende a apresentar caudas mais pesadas em relação a uma distribuição normal e/ou assimetria.

A transformação das séries em seus retornos traz consigo algumas propriedades estatísticas importantes para a modelagem dos modelos a seguir, como estacionariedade e

\footnotetext{
${ }^{1}$ Tais características serão discutidas na seção 2.4 .
} 
ergodicidade, além de eliminar os problemas de escalas nas séries. Dessa forma, as séries utilizadas no presente trabalho se referem aos retornos dos preços de exportação da Soja e do Milho.

\subsection{Modelo ARCH}

A classe dos modelos que visam modelar volatilidades tem sua origem com as formulações propostas por Engle (1982), com base nos modelos ARCH. Tais modelos possuem ampla utilização em série econômicas e financeiras, advinda da sua capacidade de modelar volatilidade. De acordo com Morettin e Toloi (2004), a ideia básica do modelo é que o retorno é não correlacionado serialmente, mas a volatilidade depende dos retornos passados por meio de uma função quadrática.

Simplificadamente, o modelo ARCH (r) pode ser definido como:

$$
\begin{aligned}
& X_{t}=\varepsilon_{t} h_{t}^{1 / 2} \\
& h_{t}=\alpha_{0}+\alpha_{1} X_{t-1}^{2}+\ldots+\alpha_{r} X_{t-r}^{2}
\end{aligned}
$$

em que $X_{t}$ é o retorno da série; $h_{t}$ expressa a função da variância; $\varepsilon_{t}$ é a sequência de variáveis aleatórias independentes e identicamente distribuídas (i.i.d) com média zero e variância igual a $1\left[\varepsilon_{t} \sim \mathrm{N}(0,1)\right]$. Os coeficientes $\alpha_{i}$ devem satisfazer certas condições, dependendo do tipo de imposição que colocamos sobre $X_{t}$, sendo que geralmente $\alpha_{0}>0$ e $\alpha_{i} \geq 0$ (MORETTIN e TOLOI, 2004).

\subsection{Modelo GARCH}

O modelo autorregressivo com heterocedasticidade condicional generalizada GARCH, foi elaborado por Bollerslev (1986), com o objetivo de obter um modelo mais parcimonioso, ou seja, com menor número parâmetros. Para tal propósito, são incluídos nesse novo modelo as variâncias passadas, além dos termos já inclusos no modelo ARCH. Assim, define-se o modelo GARCH (i,j) como:

$$
\begin{gathered}
X_{t}=\varepsilon_{t} h_{t}^{1 / 2} \\
\alpha_{0}+\sum_{i=1}^{r} \alpha_{i} X_{t-i}^{2}+\sum_{j=1}^{s} \beta_{j} h_{t-j}
\end{gathered}
$$$$
(5) h_{t}=
$$

em que $X_{t}$ é o retorno da série; $h_{t}$ expressa a função da variância, $\varepsilon_{t}$ são i.i.d $(0,1)$.

A soma $\alpha_{1}+\beta_{1}$ é conhecida por coeficiente de persistência e tem por finalidade medir a influência dos choques na volatilidade dos retornos. Se esse somatório for próximo de zero, o choque sobre a volatilidade provocará efeitos rápidos, em um curto espaço de tempo. Por 
outro lado, quanto mais próximo de um for esse resultado, mais lentamente o choque sobre a volatilidade se dissipará. E, por fim, se o coeficiente de persistência for igual ou maior que um, os choques sobre a volatilidade irão se fazer presente por um longo período de tempo (MELO e MATTOS, 2012).

\subsection{Modelos EGARCH e TARCH}

Buscando incorporar uma medida de assimetria na análise da volatilidade, os modelos EGARCH e TARCH se destacam dentro da classe dos modelos de heterocedasticidade condicional. Ressalta-se que a presença de assimetria, isto é, choques negativos impactam mais a volatilidade que os choques positivos, estão presentes em muitas séries financeiras.

Em relação ao modelo EGARCH, a assimetria é incorporada por meio de uma relação entre o retorno da série e sua variância condicional, conforme equação (7):

$$
\ln \left(h_{t}\right)=\omega+\beta \ln \left(h_{t-1}\right)+\alpha\left|\frac{r_{t-1}}{\sqrt{h_{t-1}}}\right|+\gamma\left|\frac{r_{t-1}}{\sqrt{h_{t-1}}}\right|
$$

em que $h_{t}$ é a função da variância; $r_{t-1}$ é o retorno da série defasado em 1 período; o coeficiente $\gamma$ testa a presença de assimetria na variância da série.

Por sua vez, o modelo TARCH analisa a assimetria com base na incorporação de uma variável dummy, que assume valor igual a 1 se o retorno for negativo e 0 caso contrário. Dessa forma, a especificação no modelo TARCH é dada por:

$$
h_{\mathrm{t}}=w+\alpha \mathrm{r}_{\mathrm{t}-1}^{2}+\gamma \mathrm{r}_{\mathrm{t}-1}^{2} \mathrm{~d}_{\mathrm{t}-1}+\beta h_{\mathrm{t}-1}
$$

em que $h_{\mathrm{t}}$ é a função da variância; $r_{t-1}$ é o retorno da série defasado em 1 período; $d_{t}$ a variável dummy que analisa a presença ou não de assimetria. De acordo com Morettin (2008), se $\gamma \neq 0$, há um impacto de informações assimétricas.

\subsection{Fonte de Dados}

As séries de dados utilizadas na pesquisa são compostas pelos preços da soja e do milho recebidos pelos produtores no estado do Paraná. A primeira delas se refere à Soja Industrial do Tipo 1 (saco $60 \mathrm{~kg}$ ), enquanto a segunda diz respeito ao Milho Amarelo Tipo 1 (saco $60 \mathrm{~kg}$ ), ambas coletadas junto ao Departamento de Economia Rural do Estado do Paraná $(\text { DERAL })^{2}$.

\footnotetext{
${ }^{2}$ Disponível no site: http://www.agricultura.pr.gov.br/
} 
Para obtenção dos respectivos preços de exportação, as séries de preços da soja e milho, expressas em reais (R\$), foram convertidas para o dólar americano (US\$) ${ }^{3}$. Para isso, utilizou-se a taxa de câmbio (compra), série n. 10813, disponibilizada pelo Banco Central do Brasil $^{4}$.

Por fim, destaca-se que todas as séries utilizadas são de periodicidade diária e referentes ao período compreendido entre os dias 02/01/2019 e 30/03/2021, resultando em 535 observações.

\section{Análise e Discussões dos Resultados}

Preliminarmente à estimação e análise da volatilidade dos preços de exportação da soja e do milho no estado do Paraná, serão apresentadas algumas características das séries utilizadas no presente trabalho.

\subsection{Comportamento dos preços de exportação da soja e do milho no estado do Paraná}

Com o objetivo de analisar o comportamento da variância dos preços da soja e do milho no período abarcado pela pesquisa, foram obtidos os retornos das séries como descrito na metodologia. As Figuras 1 e 2 apresentam as séries de preços de exportação da soja e do milho, no estado do Paraná, e os respectivos retornos no período de 03/01/2019 a 30/03/2021.

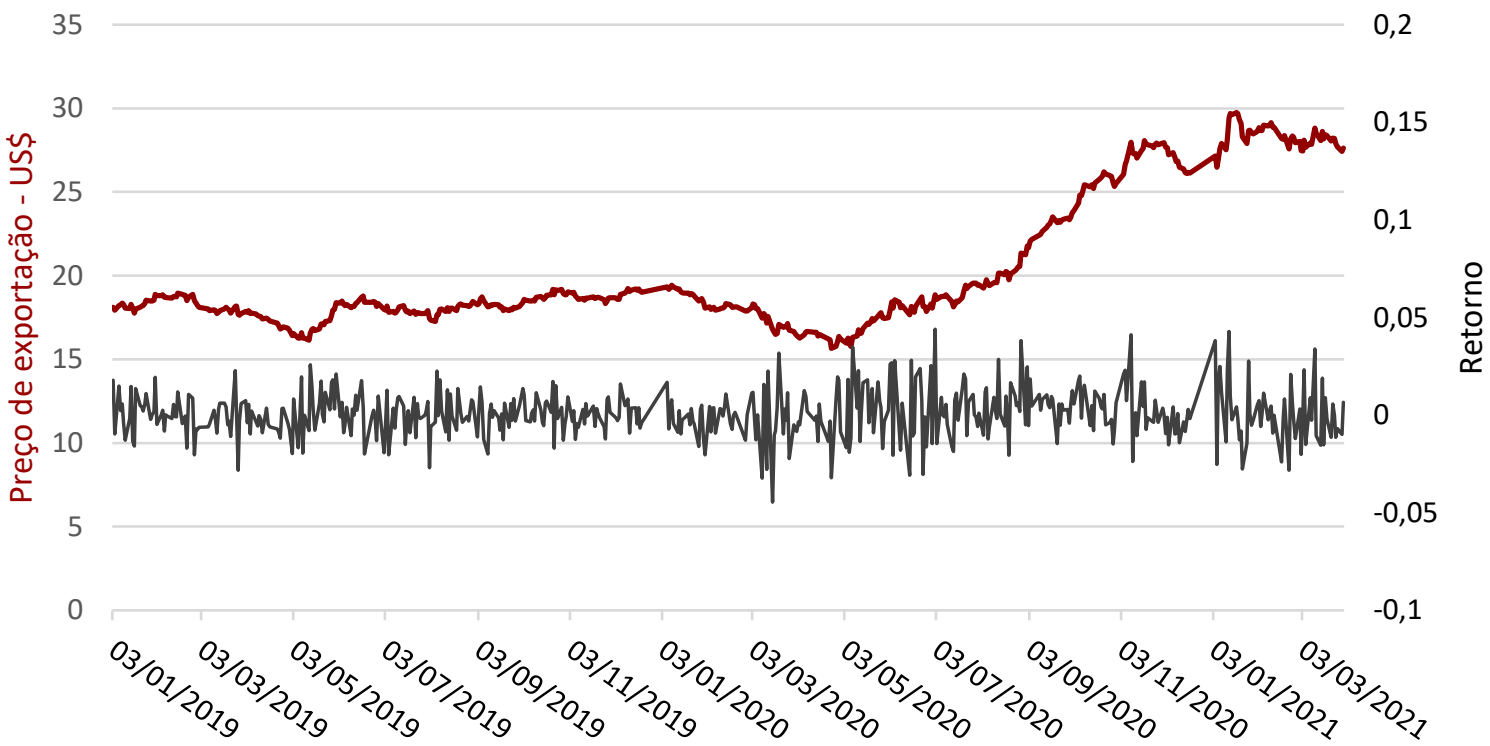

3 Tal procedimento é adotado em outros trabalhos na literatura, como Conte, Coronel e Amorim (2016) e Copetti, Coronel e Souza (2020).

${ }^{4}$ Disponível no site: https://www.bcb.gov.br/ 
Figura 1 - Preço de exportação da soja recebido pelos agricultores paranaenses e seu respectivo retorno - janeiro de 2019 a março de 2021

Fonte: Resultados da pesquisa.

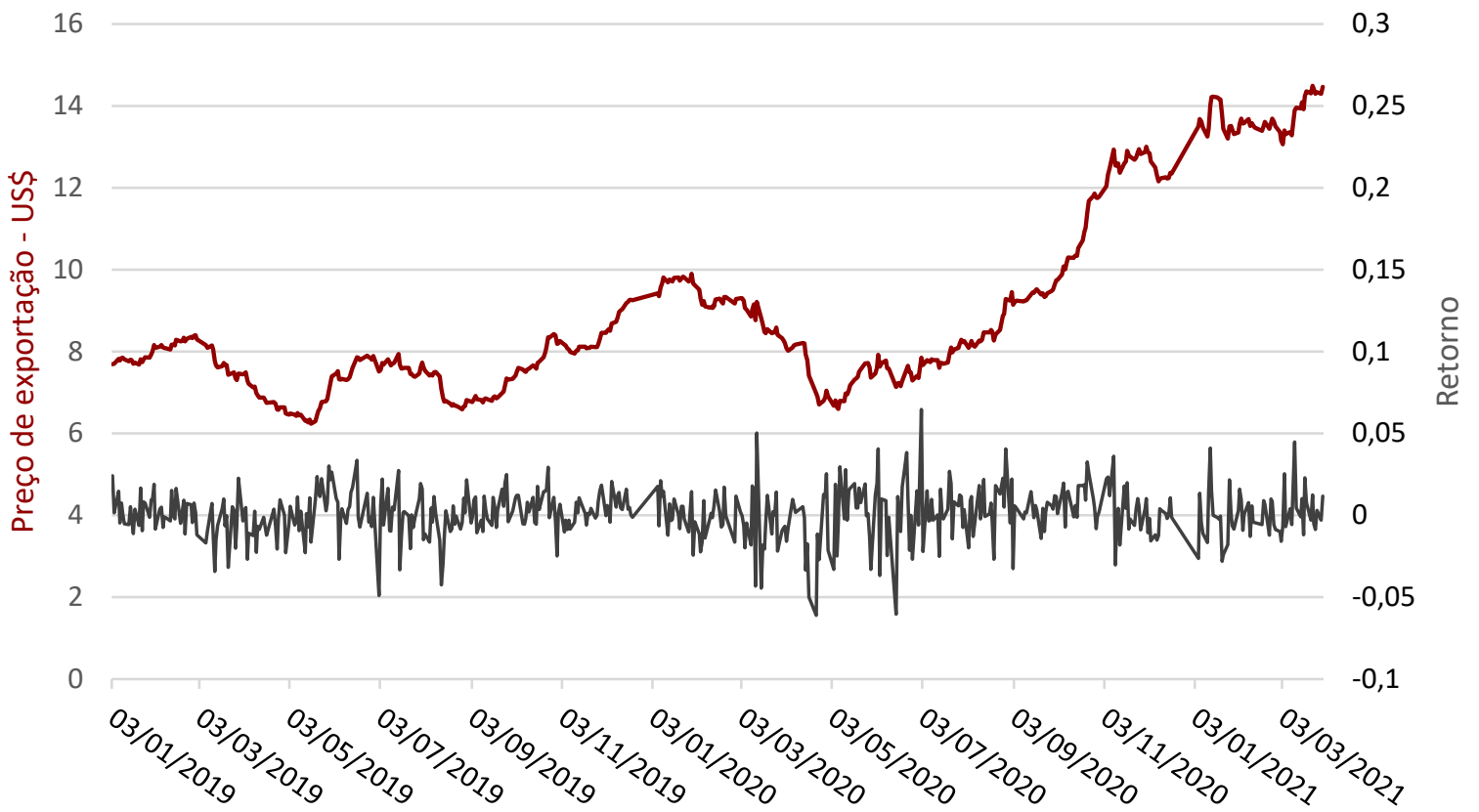

Figura 2 - Preço de exportação do milho, no estado do Paraná, e seu respectivo retorno janeiro de 2019 a março de 2021

Fonte: Resultados da pesquisa.

Pela análise das Figuras 1 e 2, é possível identificar um comportamento comum dos preços de exportação e dos retornos da soja e do milho, principalmente após o início da pandemia da Covid-19. Ambas as séries de preços de exportação apresentaram elevações em meados de maio de 2020, sendo que tais aumentos persistiram até o período final da pesquisa. Do ponto de vista dos retornos, observou-se a formação de clusters de alta volatilidade nos preços da soja e do milho no início da pandemia da Covid-19, entre março e julho de 2020.

Diante do exposto, as cotações da soja brasileira nas últimas safras foram favorecidas por dois fatores: a desvalorização do real frente ao dólar e uma maior demanda causada por problemas comerciais entre os Estados Unidos e a China que direcionaram a demanda para a soja brasileira (MOREIRA, 2020). Já para a cultura do milho, um dos motivos principais para o aumento da volatilidade foi a elevação da demanda interna e externa. No mercado doméstico a transformação em proteína contribuiu para pressionar o preço do milho, pois a suinocultura apresentou aumento significativo de sua produção, juntamente com o segmento de aves, sendo estes os principais consumidores internos do produto (GERVÁSIO, 2020).

A Tabela 2 apresenta um comparativo entre os preços e os retornos médios verificados 
antes e após a declaração de situação de pandemia de Covid-19, pela Organização Mundial da Saúde, no dia 11 de março de $2020^{5}$.

Tabela 2 - Estatísticas Descritivas dos Preços e Retornos das séries analisadas

\begin{tabular}{c|c|c|c|cc}
\cline { 3 - 6 } \multicolumn{2}{c}{} & \multicolumn{2}{c|}{ Soja } & \multicolumn{2}{c}{ Milho } \\
\cline { 3 - 6 } \multicolumn{2}{c}{} & Preço (US\$) & Retorno & Preço (US\$) & Retorno \\
\hline \multirow{2}{*}{ Média } & Pré-pandemia & 18,19 & $-0,00001$ & 7,85 & 0,00064 \\
\cline { 2 - 6 } & Pandemia & 22,67 & 0,00178 & 10,22 & 0,00144 \\
\hline \multirow{2}{*}{$\begin{array}{l}\text { Desvio- } \\
\text { padrão }\end{array}$} & Pré-pandemia & 0,64 & 0,00926 & 0,91 & 0,01240 \\
\cline { 2 - 6 } & Pandemia & 4,73 & 0,01438 & 2,57 & 0,01728 \\
\hline
\end{tabular}

Fonte: Resultados da pesquisa.

Com base na Tabela 2, os preços de exportação da soja e do milho sofreram elevação de $24,62 \%$ e $30,15 \%$, respectivamente, entre os períodos analisados. Além disso, quando comparados os valores dos desvios-padrão antes e após o início da pandemia, nota-se também uma elevação da dispersão dos preços e dos retornos das séries em estudo.

Tais resultados corroboram o fato da pandemia do novo coronavírus ter impactado na elevação dos preços e da volatilidade das duas commodities analisadas, no estado do Paraná. Nesse sentido, torna-se relevante para produtores e formuladores de políticas públicas a mensuração e estimação da volatilidade dos preços de exportação da soja e do milho.

\subsection{Procedimentos econométricos para a estimação da volatilidade dos preços de exportação da soja e do milho}

Antes de se proceder à estimação da volatilidade dos preços de exportação, a partir dos modelos de heterocedasticidade condicional, é necessário verificar se os retornos das séries de preços são estacionários. Como ressaltado na seção 2.1, a transformação das séries em seus retornos traz consigo algumas propriedades estatísticas importantes para a modelagem, como a estacionariedade, sendo essa confirmada pelos testes Augmented Dickey-Fuller (ADF), Phillips-Perron (PP) e Kwiatkowski-Phillips-Schmidt-Shin (KPSS).

Dado que as variáveis a serem incluídas na modelagem da volatilidade são estacionárias, parte-se para a pré-filtragem dos dados a fim de remover a correlação serial

${ }^{5}$ Para maiores informações, ver https://news.un.org/pt/story/2020/03/1706881. 
existente no primeiro momento das séries de retornos. Dessa forma, foram estimados modelos $\operatorname{ARMA}(p, q)$ para as equações das médias de cada série dos retornos dos preços da soja e do milho, sendo analisada a presença de autocorrelação nos resíduos por meio do teste de Multiplicador de Lagrange de Breusch-Godfrey. Para definição da ordem do modelo ARMA a ser estimado, foi adotado o procedimento seguido por Alexander (2005) e Tsay (2010), em que se busca a especificação mais parcimoniosa possível para a equação da média ${ }^{6}$.

A Tabela 3 sumariza os modelos estimados para as equações da média de cada série analisada, bem como o teste de Breusch-Godfrey para verificar a presença de autocorrelação serial nos resíduos das equações.

Tabela 3 - Teste Multiplicador de Lagrange Breusch-Godfrey para detectar a presença de autocorrelação nos resíduos das equações da média dos retornos

\begin{tabular}{cccc}
\hline & $\begin{array}{c}\text { Equação da Média } \\
\text { Retorno }\end{array}$ & Estatística & P-valor \\
\hline Soja & $\operatorname{AR}(p, q)$ & 1,291108 & 0,2564 \\
\hline Milho & $\operatorname{ARMA}(1,1)$ & 0,093379 & 0,7600 \\
\hline
\end{tabular}

Fonte: Resultados da pesquisa.

Nota: As defasagens utilizadas nos testes seguiram o critério de informação de Schwartz.

Os resultados apresentados na tabela anterior confirmam a ausência de autocorrelação serial nos resíduos das respectivas equações da média, uma vez que a hipótese nula (ausência de autocorrelação) não foi rejeitada em todos os casos.

A etapa seguinte consistiu na realização do teste do multiplicador de Lagrange proposto por Engle (1982) para verificar a presença de heterocedasticidade condicional na série de retorno, fato estilizado como efeito ARCH na literatura. Caso o efeito ARCH seja identificado nos resíduos da equação da média ${ }^{7}$, estimada na etapa anterior, justifica-se o uso da modelagem de heterocedasticidade condicional para estimar as respectivas volatilidades. Assim, a Tabela 4 expõe o teste de Engle (1982) para detectar a presença de estrutura ARCH nos resíduos dos modelos.

\footnotetext{
${ }^{6}$ Neste processo, cabe atentar para o fato de o objetivo principal na estimação do modelo se referir à equação da variância condicional (BAUWENS et al., 2006), sendo, portanto, usual adotar uma equação simples para a média condicional (ALEXANDER, 2005).

7 No caso de os resíduos apresentarem heterocedasticidade condicional, a série de retornos também apresentará o efeito $\mathrm{ARCH}$.
} 
Tabela 4 - Teste de Engle para detectar a presença do efeito ARCH nas séries de retorno

\begin{tabular}{cccc}
\hline Retorno & $\begin{array}{c}\text { Equação da Média } \\
\text { ARMA }(p, q)\end{array}$ & Estatística & P-valor \\
\hline Soja & $\operatorname{AR}(1)$ & 8,777257 & 0,0002 \\
\hline Milho & $\operatorname{ARMA}(1,1)$ & 19,28994 & 0,0000 \\
\hline
\end{tabular}

Fonte: Resultados da pesquisa.

Nota.: As defasagens utilizadas nos testes seguiram o critério de informação de Schwartz.

Em todos os índices analisados, a hipótese nula de ausência de efeito $\mathrm{ARCH}$ foi rejeitada, confirmando, portanto, a presença de volatilidade condicional nos retornos dos preços da soja e do milho.

De modo geral, a partir das evidências obtidas pelos testes descritos nas Tabelas 3 e 4, foi possível concluir que a pré-filtragem dos dados foi bem-sucedida, uma vez que forneceu resíduos livres de correlação serial, que serão utilizados na modelagem da variância condicional na próxima etapa.

Com o objetivo de estimar a volatilidade dos preços de exportação da soja e do milho, no estado do Paraná, entre janeiro de 2019 e março de 2021, foram estimados os modelos de heterocedasticidade condicional para cada série de preços $^{8}$.

A seguir, apresentar-se-á o modelo que obteve o melhor ajuste ${ }^{9}$ para cada série de preços, a fim de possibilitar uma análise mais detalhada do comportamento da volatilidade em cada mercado.

\subsection{Análise da volatilidade dos preços de exportação da soja e do milho no estado do Paraná}

Como ressaltado na seção 1, a soja e o milho são commodities de grande importância para a economia do estado do Paraná, seja pela criação de receitas via exportação, ou pela geração de renda para milhares de famílias que participam da cadeia de produção desses produtos. Após o início da pandemia da Covid-19, o que se verificou nesses dois mercados foi a elevação dos preços de exportação da soja e do milho, concomitante a formação de clusters de alta volatilidade nos respectivos retornos dos preços.

\footnotetext{
${ }^{8}$ Foram estimados os modelos ARCH, GARCH, EGARCH e TARCH, como descrito na metodologia. Utilizou-se a matriz de correção de variância-covariância, proposta por Bollerslev \& Wooldridge (1992), na estimação, uma vez que os resíduos dos modelos ajustados para a equação da média condicional de cada série analisada não se aproximaram da distribuição normal.

${ }^{9}$ Para definição da ordem dos modelos, utilizou-se o critério de informação de Schwartz.
} 


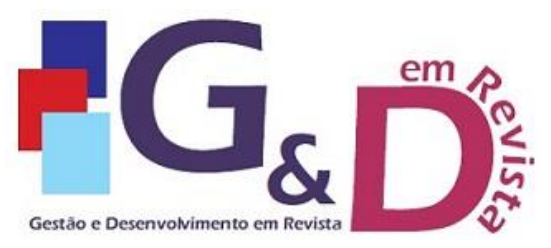

Gestão e Desenvolvimento em Revista

V. 8, N. 2, jul-dez/2021, p. 133-152.

ISSN online: $2446-8738$

Artigo recebido em: 02/08/2021

Artigo aprovado em: 27/10/2021

Para analisar detalhadamente o comportamento da volatilidade estimada, serão apresentadas as estimativas para cada commodity nas duas seções a seguir.

\subsubsection{Volatilidade estimada do preço de exportação da soja}

O modelo que apresentou o melhor ajuste para a volatilidade da soja foi o $\operatorname{GARCH}(1,1)^{10}$, cuja estimativa da equação da variância está listada na Tabela 5.

Tabela 5 - Resultado do modelo GARCH para o preço de exportação da soja

\begin{tabular}{ccccc}
\hline \multicolumn{5}{c}{ Método: ML - GARCH (Marquardt) } \\
\hline \multicolumn{5}{c}{ Série de retorno - Preço exportação Soja } \\
\hline & Coeficiente & Erro-padrão & Estatística Z & Prob. \\
\hline AR(1) & $-0,088177$ & 0,042559 & $-2,071883$ & 0,0383 \\
\hline \multicolumn{5}{c}{ Equação da variância condicional } \\
\hline CRCH (1) & 0,000015 & 0,000006 & 2,299763 & 0,0215 \\
GARCH (1) & 0,129736 & 0,041735 & 3,108542 & 0,0019 \\
\hline \hline
\end{tabular}

Fonte: Resultados da pesquisa.

Com base nos resultados apresentados pela Tabela 5, observou-se que todos os parâmetros do modelo foram estatisticamente significativos ao nível de 5\%. Quando analisada a persistência de choques na volatilidade da soja, medida pela soma dos coeficientes ARCH (1) e GARCH(1), o valor estimado foi de 0,90, indicando alta persistência. Esse resultado mostra que choques sobre a volatilidade se dissiparam mais lentamente no período analisado.

Cabe ainda ressaltar que não foi verificada a presença de assimetria na volatilidade dos preços de exportação da soja no período analisado, uma vez que os parâmetros que medem tal efeito não foram significativos nos modelos EGARCH e TARCH. Tal resultado sugere que, durante a pandemia da Covid-19, a volatilidade do preço da soja não respondeu de maneira diferente a choques positivos ou negativos.

A volatilidade condicional estimada pelo modelo $\operatorname{GARCH}(1,1)$ para o preço de exportação da soja, entre janeiro de 2019 e março de 2021, está mostrada na Figura 3.

\footnotetext{
10 Os testes realizados para diagnosticar a adequabilidade do modelo confirmaram seu bom ajuste, uma vez que o correlograma dos resíduos do modelo rejeitou a presença de autocorrelação serial e o Teste $\mathrm{ML}$ indicou a rejeição da presença de efeito $\mathrm{ARCH}$ nos resíduos, demonstrando que a especificação $\operatorname{GARCH}(1,1)$ obteve sucesso em modelar a volatilidade dos retornos do preço da soja.
} 


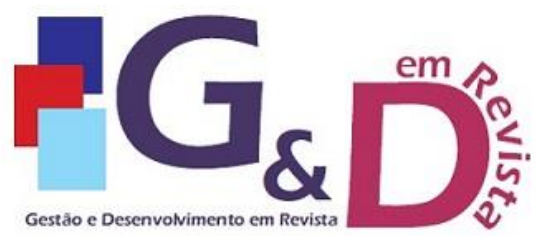

\section{6,00E-04}

$5,00 \mathrm{E}-04$

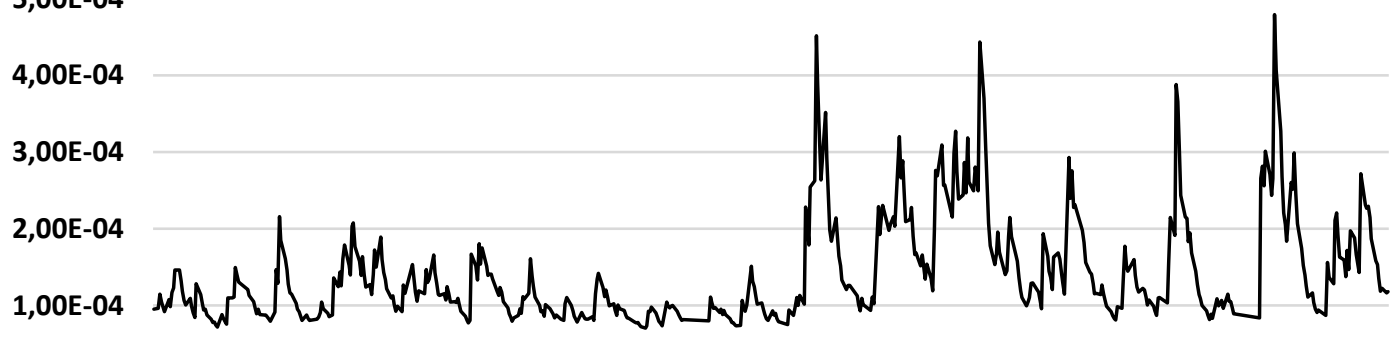

$0,00 E+00$

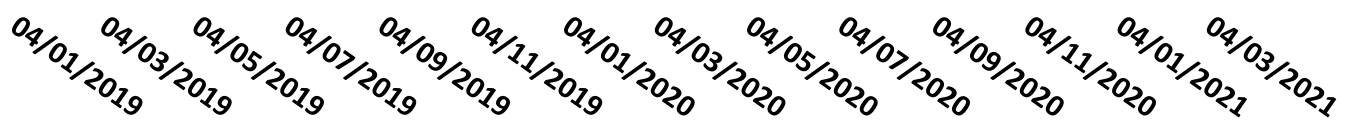

Figura 3 - Volatilidade estimada pelo modelo GARCH $(1,1)$ para o preço de exportação da soja no estado do Paraná - janeiro de 2019 a março de 2021

Fonte: Resultados da pesquisa.

A partir da Figura 3, foi possível verificar o aumento na volatilidade do preço de exportação da soja após o início da pandemia pelo novo coronavírus, mais especificamente entre e março e abril de 2020. Comparando o valor da variância estimada antes e depois do início da pandemia, observou-se um aumento de 69\%. Assim, os preços de exportação da soja no estado do Paraná se mostraram mais voláteis no período do novo coronavírus.

Tal resultado, quando analisado em conjunto com a Figura 1 (na seção 3.1) revela especificidades importantes no mercado agroexportador paranaense. A primeira delas é a de que o processo de alta nos preços de exportação da commodity, após o início da pandemia, foi acompanhado pelo aumento da volatilidade. Outro ponto é que a volatilidade dos preços manteve-se elevada durante todo o período de pandemia, não retornando aos níveis verificados pré-pandemia. Isso corrobora a alta persistência estimada pelos coeficientes do modelo GARCH $(1,1)$, que foi de 0,90 .

\subsubsection{Volatilidade estimada do preço de exportação do milho}

O modelo $\operatorname{GARCH}(1,1)^{11}$ foi o que obteve o melhor ajuste para modelar a volatilidade condicional do preço de exportação do milho. A estimativa da equação da variância é mostrada na Tabela 6.

${ }^{11}$ Os testes realizados sobre os resíduos do modelo estimado indicaram ausência de autocorrelação serial e rejeição da presença de efeito $A R C H$, de modo que a especificação GARCH $(1,1)$ obteve bom ajuste em modelar a volatilidade dos retornos do preço do milho. 
Tabela 6 - Resultado do modelo GARCH para o preço de exportação do milho

\section{Método: ML - GARCH (Marquardt)}

Série de retorno - Preço exportação Milho

\begin{tabular}{ccccc}
\hline & Coeficiente & Erro-padrão & Estatística Z & Prob. \\
\hline AR(1) & 0,916840 & 0,045252 & 20,26080 & 0,0000 \\
\hline MA(1) & $-0,836543$ & 0,060935 & $-13,72846$ & 0,0000 \\
\hline \multicolumn{7}{c}{ Equação da variância condicional } \\
\hline C & 0,000014 & 0,000007 & 1,977171 & 0,0480 \\
ARCH (1) & 0,111915 & 0,040641 & 2,753762 & 0,0059 \\
GARCH (1) & 0,827465 & 0,060304 & 13,72147 & 0,0000 \\
\hline \hline
\end{tabular}

Fonte: Resultados da pesquisa.

Os resultados da Tabela 6 demonstram semelhança com os obtidos para a soja, porém com algumas especificidades. Nesse sentido, os parâmetros do modelo foram estatisticamente significativos ao nível de 5\%. Em relação à persistência de choques na volatilidade do milho, o valor estimado foi de 0,94 , sendo esse superior ao estimado para a soja, e indicou alta persistência. Portanto, os choques sobre a volatilidade do milho se dissiparam lentamente no período analisado, assim como verificado para a soja.

Outro importante resultado, também observado para a soja, foi que a assimetria em relação aos choques na volatilidade do milho não foi identificada pelos parâmetros dos modelos EGARCH e TARCH estimados.

A Figura 4 reporta a volatilidade condicional estimada pelo modelo GARCH $(1,1)$ para o preço de exportação do milho, entre janeiro de 2019 e março de 2021.

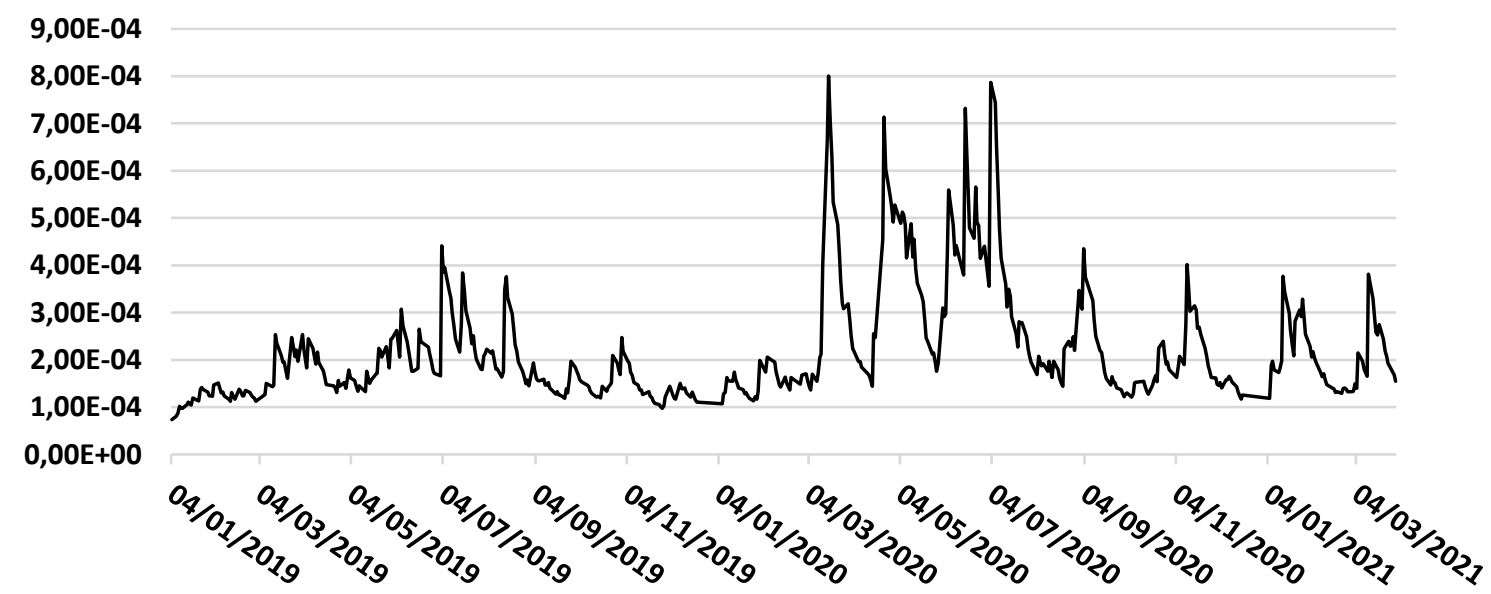

Figura 4 - Volatilidade estimada pelo modelo GARCH $(1,1)$ para o preço de exportação do milho no estado do Paraná - janeiro de 2019 a março de 2021

Fonte: Resultados da pesquisa. 


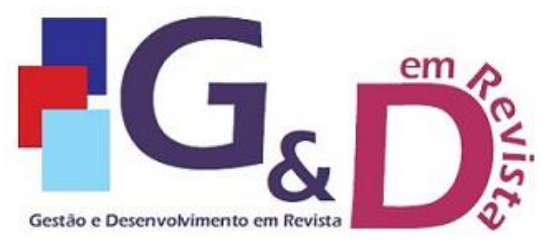

Gestão e Desenvolvimento em Revista

V. 8, N. 2, jul-dez/2021, p. 133-152.

ISSN online: $2446-8738$

Artigo recebido em: 02/08/2021

Artigo aprovado em: 27/10/2021

Foi possível identificar a elevação da volatilidade dos preços de exportação do milho, a partir do início da pandemia da Covid-19. Nesse caso, o aumento da variância estimada entre os períodos antes e após a pandemia foi de aproximadamente $60 \%$, evidenciando que os preços da commodity passaram a apresentar maior volatilidade. Porém, o período de maior volatilidade se concentrou nos meses iniciais da pandemia, entre março e julho de 2020, diferentemente da volatilidade do preço de exportação da soja, que permaneceu em patamares elevados até março de 2021.

Em síntese, as variâncias estimadas dos preços de exportação da soja e do milho no período analisado evidenciaram elevações significativas nas volatilidades após o início da pandemia da Covid-19, além de identificarem a presença de alta persistência de choques sobre as respectivas volatilidades.

\section{Considerações finais}

A pandemia da Covid-19 tem afetado praticamente todos os países do globo e lançado novos desafios para os formuladores de políticas de diversas áreas. Na conjuntura brasileira, um desses reflexos recai sobre o aumento de preços dos alimentos, o que é atribuído, em parte, tanto devido ao aumento da demanda externa quanto também pela desvalorização do Real, gerando, assim, um efeito combinado no aumento da volatilidade dos preços.

Neste contexto, o presente trabalho analisou o comportamento dos preços de exportação recebidos pelos produtores de soja e milho no estado do Paraná, entre janeiro de 2019 e março de 2021. Para tanto, empregou-se modelos de variância condicional com o intuito de estimar a volatilidade das referidas séries e inferir se houve elevação dessa medida após o início da pandemia da Covid-19. Ademais, a metodologia proposta permitiu verificar qual grupo de produtores foi mais suscetível a tais oscilações de preços.

De modo geral, os resultados identificaram aumento na volatilidade dos preços de exportação da soja e do milho, sendo esse comportamento mais acentuado após o início da pandemia. No caso da soja, a volatilidade condicional elevou-se em aproximadamente $70 \%$, isso entre o período anterior e após a declaração da pandemia pelo novo coronavírus. Ressalta-se, ainda, que tal aumento não se restringiu aos meses iniciais da pandemia, sendo prolongado até o $1^{\circ}$ trimestre de 2021.

Em relação ao milho, o padrão observado foi semelhante ao caso da soja, embora a magnitude do aumento da volatilidade tenha sido inferior, na ordem de $60 \%$. Além disso, a 


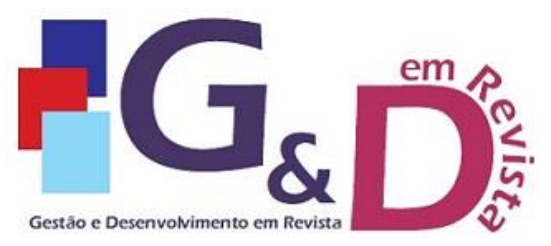

Gestão e Desenvolvimento em Revista V. 8, N. 2, jul-dez/2021, p. 133-152.

ISSN online: $2446-8738$

Artigo recebido em: 02/08/2021

Artigo aprovado em: 27/10/2021

elevação da volatilidade para os preços de exportação do milho se concentrou entre os meses de março e julho de 2020.

Tais resultados evidenciam a alta persistência de choques nos preços da soja e do milho no período analisado, bem como constatam que os produtores de soja foram mais expostos à volatilidade no preço da commodity que os produtores de milho.

Como sugestão para trabalhos futuros, recomenda-se analisar a transmissão da volatilidade entre os preços de soja e milho, utilizando modelos de variância condicional multivariados. Aconselha-se, também, a realização estudos capazes de averiguar qual o impacto de tais oscilações nos índices inflacionários e como eles se dissiparão ao longo do tempo.

\section{Referências}

ALEXANDER, C. Modelos de Mercado: Um Guia para a Análise de Informações Financeiras. São Paulo: Bolsa de Mercadorias \& Futuros, 2005.

BANCO CENTRAL DO BRASIL. Taxa de câmbio livre - Dólar americano (venda) Média de período - mensal. 2021. Disponível em:

https://www3.bcb.gov.br/sgspub/localizarseries/localizarSeries.do?method=prepararTelaLoca lizarSeries Acesso em: 02 mai. 2021.

BAUWENS, L.; LAURENTE, S.; ROMBOUTS, J. V. K. Multivariate Garch Models: A Survey. Journal of Applied Econometrics, v. 26, n. 4, p. 79-109, 2006.

BOLLERSLEV, T. Generalized autoregressive conditional heteroscedasticity. Journal of Econometrics, v. 31, n. 3, p. 307-327, 1986.

BOLLERSLEV, T.; WOOLDRIDGE, J. M. Quasi-Maximun Likelihood Estimation and Inference in Dynamic Models with Time-Varying Covariances. Econometric Reviews, v.11, n.2, p.143-172, 1992.

BRASIL. Ministério da Economia. Exportação e importação em geral. 2021.

Disponível em: http://comexstat.mdic.gov.br/pt/home Acesso em: 30 abr. 2021.

CAMPOS, K. C. Análise da volatilidade de preços de produtos agropecuários no Brasil.

Revista de Economia e Agronegócio, v. 5, n. 3, p. 303-328, 2007.

CONTE, B. P.; CORONEL, D. A.; AMORIM, A. L. Análise da volatilidade do complexo brasileiro de soja em relação ao mundo. Revista de Política Agrícola, n. 2, p. 26-38, 2016.

COPETTI, L.S.; CORONEL, D. A.; SOUZA, A. D. Transmissão da variação da taxa de câmbio para os preços de exportações brasileiras da carne bovina e da carne de frango (19972019). Revista Gestão e Planejamento, Salvador, v. 21, p. 675-697, 2020. 
ENGLE, R. F. Autoregressive conditional heteroskedasticity with estimates of the variance of U.K. inflation. Econometrica, v. 50, n. 4, p. 987-1008, 1982.

GERVÁSIO, E. W. Prognóstico Cultura MILHO. Dezembro de 2020. Secretaria da Agricultura e do Abastecimento do Paraná - Departamento de Economia Rural. Divisão de Conjuntura Agropecuária. 2020. Disponível em:http://www.agricultura.pr.gov.br/sites/default/arquivos_restritos/files/documento/202012/Progn\%C3\%B3stico\%20Milho\%20-\%202021.pdf. Acesso em: 10 mai. 2021.

INSTITUTO BRASILEIRO DE GEOGRAFIA E ESTATÍSTICA (IBGE). Pesquisa Agrícola Municipal, 2019. Disponível em:

https://www.ibge.gov.br/estatisticas/economicas/agricultura-e-pecuaria/9117-producaoagricola-municipal-culturas-temporarias-e-permanentes.html?=\&t=resultados Acesso em: 02 mai. 2021.

INSTITUTO PARANAENSE DE DESENVOLVIMENTO ECONÔMICO E SOCIAL (IPARDES). PIB Trimestral do Paraná. 2021. Disponível em:

http://www.ipardes.pr.gov.br/Pagina/PIB-Trimestral-do-Parana Acesso em: 20 jul. 2021.

LÜTKEPOHL, H.; KRÄTZIG, M. Applied Time Series Econometrics. Cambridge: Cambridge University Press, 2004.

MANFIO, D. A. Estiagem Histórica no Paraná. Maio de 2020. Secretaria da Agricultura e do Abastecimento do Paraná - Departamento de Economia Rural. 2020a. Disponível em: https://www.agricultura.pr.gov.br/Pagina/Estiagem-2 Acesso em: 24 jun. 2021.

MANFIO, D. A. Condições Climáticas - Estiagem. Outubro de 2020. Secretaria da Agricultura e do Abastecimento do Paraná - Departamento de Economia Rural. 2020b. Disponível em: https://www.agricultura.pr.gov.br/Pagina/Condicoes-Climaticas Acesso em: 24 jun. 2021.

MELO, E. M.; MATTOS, L. B. Análise da volatilidade da base do café arábica para a mesorregião do sul de Minas Gerais. Revista Economia \& Gestão, v. 12, n. 29, p. 124-140, 2012.

MOREIRA, M. G. Prognóstico Cultura SOJA. Dezembro de 2020. Secretaria da Agricultura e do Abastecimento do Paraná - Departamento de Economia Rural. 2020. Disponível em:

https://www.agricultura.pr.gov.br/sites/default/arquivos_restritos/files/documento/202012/Prognostico\%20Soja\%20-\%202020_21.pdf Acesso em: 24 jun. 2021.

MORETTIN, P. A. Econometria Financeira: Um Curso em Séries Temporais Financeiras. São Paulo: Editora Blucher, 2008.

MORETTIN, P.A.; TOLOI, C.M.C. Análise de Séries Temporais. São Paulo: Editora Edgard Blucher, 2004. 


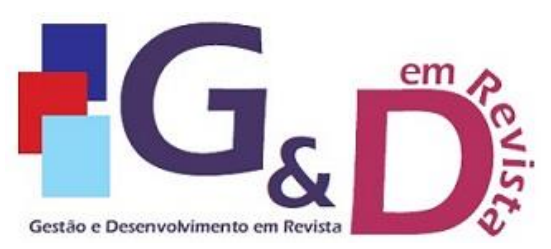

Gestão e Desenvolvimento em Revista V. 8, N. 2, jul-dez/2021, p. 133-152. ISSN online: $2446-8738$

Artigo recebido em: 02/08/2021

Artigo aprovado em: 27/10/2021

NONNENBERG, M. J. B. Contas externas e taxa efetiva real de câmbio. Cartas de conjuntura, IPEA, n. 50, nota de conjuntura 23, p. 1-11, jan./mar., 2021.

SILVA, W.S.; SÁFADI, T.; CASTRO JUNIOR, L.G. Uma análise empírica da volatilidade do retorno de commodities agrícolas utilizando modelos ARCH: os casos do café e da soja. Revista de Economia e Sociologia Rural, v. 43, n. 1, p. 119-134, 2005.

STIGLITZ, J. E.; OCAMPO, J.; SPIEGEL, S; FRENCH DAVIS, R.; NAYYAR, D. Stability with Growth: Macroeconomics, Liberalization and Development. New York: Oxford Uni Press, 2006.

TSAY, R. S. Analysis of Financial Time Series. 3. Ed. New Jersey: Wiley, 687 p., 2010. 1 